\title{
Structural Racism and Supporting Black Lives - A Pharmacist's Vow amid COVID-19
}

Nicole D. Avant, PharmD, BCACP

University of Cincinnati Experience-Based Learning and Career Education

\begin{abstract}
COVID-19 is disproportionately impacting Black communities in the United States due to racial structures that increase exposure (e.g., densely populated areas, substandard housing, overrepresentation in essential work) and promote underlying diseases that exacerbate COVID-19. This manuscript uses Oath of a Pharmacist as a framework to propose a set of best practices for pharmacists to mitigate inequities such as achieve competence in the ideology of structural racism; identify systems of power that jeopardize Black health; value Black voices; name the socio-structural determinants of health; define race as a socio-political construction; name historical and contemporary racism; apply resources equitably based on need; collect robust data to solve complex problems; diminish bias and view patients holistically in the contexts of inequities; and advocate for Black lives. While race is biological fiction, Black individuals are at an increased risk for COVID-19 cases, hospitalizations, and deaths than their white counterparts due to navigating generations of racist practices that often converge with other inequities - such as sexism, classism. To describe these racial health disparities, structured, racial disadvantage is commonly ignored while personal choices and clinical care are highlighted as the culprits. Achieving health equity requires comprehension, acceptance, and assessment of structural racism, and pharmacists are highly trusted, uniquely positioned healthcare professionals who, through their knowledge, skills, and resources, can help attenuate the effects of structural racism to support Black lives.
\end{abstract}

Keywords: structural competence, health inequalities; health inequities; medically underserved groups; social inequalities in health, social determinants of health, structural determinants of health, health equity, Black health

According to the 2010 United States Census, Black people make up $13 \%$ of the US population. ${ }^{1}$ Yet, data from the Center for Disease Control \& Prevention (CDC) pertaining to the novel coronavirus reveal that non-Hispanic Black people comprise approximately $28 \%$ of the nation's coronavirus disease 2019 (COVID-19) cases, $37 \%$ of hospitalizations, and $21 \%$ of deaths. ${ }^{2-4}$ Disproportionate rates are evident throughout the country, including - but not exclusive to - hot spot cities such as Chicago, Milwaukee, and New York City. In Southern states, like Alabama and Louisiana, some areas report Black people account for $70 \%$ of deaths. ${ }^{5}$ Such glaringly disproportionate representation of Black residents at the local, state, and federal levels among COVID-19 patients demands immediate attention and begs an explanation.

Health outcomes are influenced by many factors. Of the modifiable contributors to health outcomes, health behaviors, socio-economic conditions, physical environments, and clinical care have an estimated weighted distribution of $30 \%, 40 \%, 10 \%$, and $20 \%$, respectively. ${ }^{6}$ When individuals are confronted with racial disparities such as COVID-19 differences, however, their thinking is often guided by a personal choice model that dictates that differences can be explained by variables such as morals, character, values, knowledge of disease, and education level. ${ }^{7}$

Corresponding author: Nicole D. Avant, PharmD, BCACP University of Cincinnati Experience-Based Learning and Career Education 735 Joseph A. Steger Student Life Center

Cincinnati, Ohio 45221

Phone: 513-558-8254; Email: nicole.avant@uc.edu
This personal choice model is significantly limited as it dismisses at best, or is oblivious at worst, to the impact of centuries long structural inequities that served as the early, fertile ground for contemporary conditions. This manuscript highlights structural factors that contribute to observed racial health inequities in the United States COVID-19 health crisis and suggests approaches that pharmacists may take in accordance with the Oath of a Pharmacist.

While health behaviors such as poor nutrition, low levels of physical activity, tobacco use, excessive alcohol use-and more recently social-distancing and mask-wearing-are important determinants of health, it is significantly reductive to describe health solely utilizing health behaviors. ${ }^{6}$ It is vital to look beyond health behaviors to include the contexts within which people engage in said health behaviors and are able to make informed decisions/choices like having both the means and opportunity to access affordable, nutritious foods, and safe spaces for physical activity. It is possible to make better/healthier choices when there is open and unrestricted access to better/healthierchoices and the absence of stress associated with discrimination, indignities, violence, erasure, and shame. Personal choices must be assessed in the context of social and structural factors in which patients live, work, eat, play, pray, and otherwise exist.

Of the health factors contributing to health outcomes, socioeconomic factors such as education, income, essential employment, family/social support, and community safety carry the highest weight, yet ironically, are the most ignored. ${ }^{6}$ These factors are more significant than personal choices and fundamental as ensuring these can promote healthy behaviors. Positive socioeconomic factors unsurprisingly reinforce one 
another and have the benefit to increase life expectancy as having gainful employment increases the likelihood that one can make healthy choices, access healthcare, afford safe housing, avoid concentrated poverty, access tax dollars for good education, and accumulate savings to cushion economic distress such as national stay home orders.

Another fundamental component of health includes thephysical environment. Data illustrates being born and raised in underresourced zip codes can increase premature morbidity and mortality. ${ }^{6}$ Individuals without access to clean air, safe water, stable housing, reliable/consistent transit, as well as residing in densely populated areas and substandard housing, have disproportionately increased risks for cancer, infections, asthma, and other lung diseases. For COVID-19, the county/corporate responses of water shut-offs in living spaces, posed a potential structural vulnerability to health in that the act prevented handwashing. The physical environment also impacts the spread of COVID-19.

Finally, access to quality, clinical care is a factor of health. ${ }^{6}$ Lack of access to insurance, incurring high deductibles, significant distance to clinicians, and absence of specialists in networks, impact the ability of clinicians to diagnose patients early in treatable stages. The frequent reports of patients being sent home multiple times with untreated COVID-19 symptoms after presenting with clear symptoms is, regrettably, how inequitable access to quality clinical care continue to manifest during this pandemic.

It is critical to assess the groups of people who are structurally disadvantaged and possess less than favorable access to healthy personal choices, high socioeconomic status, resourced physical environments, and high-quality clinical care. Black people in America have historically - through both law and custom-been collectively pushed to the margins of society by racist laws, policies, practices, and norms within local and national institutional structures and systems such as redlining, urban renewals, education funding gaps, vastly undervalued homes, and predatory lending that prefer whiteness to Blackness. Wellness and survival during a global pandemic require an alleviation of inequitable structures that encourage concentrated poverty and health vulnerabilities. Personal choices alone cannot explain the stark and significant disparities in cases, hospitalizations, and deaths, which should compel a revolutionary reckoning with and confrontation against racebased health inequities. With candor, education, empathy, and intentional training, it is possible to achieve health equity. In order to do so, pharmacists must co-strategize with others to dismantle institutional and structural racism.

Dr. Camara Jones, a former medical officer for the Centers for Disease Control (CDC), defines structural/institutional racism as "differential access to the goods, services, and opportunities of society by race." ${ }^{8}$ Although COVID-19 impacts everyone, the impact on health varies greatly demographically. The rate of infection for Black individuals is higher than their white counterparts likely due to increased exposure (e.g., residing in densely populated areas, access to substandard housing, overrepresentation in essential work). It is worth considering the ways in which existent racial and social stressorsgenerational and vicarious trauma, discrimination, vigilance and anticipatory stress, residential segregation, differential access to societal goods and resources, and internalized racism-have potentially influenced hospitalization and death rates within Black communities by increasing their susceptibility to COVID-19 complications. ${ }^{9}$ Additionally, disparate clinical care (e.g., reduced testing availability in predominately Black neighborhoods, health systems refusing to admit Black patients) could be a contributing factor in COVID-19 racial disparities. In a recent interview, Dr. Jones, physician and epidemiologist stated:

"What the COVID-19 pandemic is unveiling is the structural racism, which is why we see people of color and poor people more profoundly impacted. This virus is an equal- opportunity virus, but this disease is not an equal- opportunity disease, and it's manifesting itself more severely in people of color who've been historically oppressed and disinvested. So the way that you need to talk about racism in this time is to explain, to make it clearto everybody looking at this, that it's not some kind of inherent weakness of African Americans that's making them die more frequently of the disease than other people in Milwaukee, in Detroit. That is an impact of racism, so what we need to do is un-invisiblize structural racism and say this structural racism and the historical federalpartitioning of our cities into racially segregated neighborhoods, the disproportionate placement of toxic dump sites, that stuff which is giving us more asthma, morelung disease, or the HIV epidemic-these are the old aspects of racism showing up during this pandemic. This isracism showing up...We need to label the racism that it is." 10

Racism operates at multiple levels: internalized, interpersonal, institutional, and structural. ${ }^{8}$ COVID-19 is highlighting the subtleties of structural racism. This disease concretizes the role of racism in sickness and death among Black Americans. Structural racism operates and persists even with the best of intentions, and it would be irresponsible folly for our profession to presume/assume that pharmacists are somehow immune to the hidden biases that are rampant in our society. ${ }^{11}$ Unlike internalized and interpersonal racism, however, structural racism and consequently racial health differences do not need a perpetrator to persist and thrive.

This manuscript was inspired by an article written in The New England Journal of Medicine for medical clinicians and researchers to support Black Lives. ${ }^{12}$ This necessary piece of literature stated clinicians should learn, confront, and accept the roots of racism in America, understand how racism causes health professionals to engage in biological determinism to describe racial health differences, define and name racism in our work and to provide equitable clinical care and research that centers and amplifies marginalized voices. Although pharmacists are not 
specifically named in this document, it is clear pharmacists have a role. Pharmacists are so well-positioned to mitigate the impacts of structural racism and protect the health of patients at the margins and extreme margins of society. Utilizing the "Oath of a Pharmacist" as a framework in addition to a more intentional understanding of the positionality of our field, pharmacists can serve and support Black lives. ${ }^{13}$

The pharmacists oath asks pharmacists to:

- accept the lifelong obligation to improve professional knowledge and competence

- hold the highest principles of moral, ethical, and legal conduct

- consider the welfare of humanity and relief of suffering as primary concerns

- assure optimal outcomes for patients

- respect and protect all personal and health information

- advocate for change

- prepare the next generation of pharmacists.

Ideologically, this Oath could protect the health of our most harmed and neglected populations. Realistically, the Oath has not been used to dismantle racist systems that jeopardize the health of Black communities. The following recommendations provide concrete immediate examples of how the Oath of a Pharmacist could be used to support Black lives

\section{Recommendation 1: Become structurally competent by identifying systems of power that jeopardize Black health}

Oath 1: "I will accept the lifelong obligation to improve my professional knowledge and competence."

Collectively, pharmacists have not comprehended the ways inequities of social, economic, and political systems shape the lives and consequently the health of patients. Navigating a lifetime of chronic stress, hypervisibility, invisibility, violence, and disempowerment takes a toll physically and psychologically on not only patients but their subsequent descendants. Inattention to systems of power cultivates immeasurably incompetent pharmacists. Structural competency regarding institutions and systems/structures that impair health is necessary. ${ }^{14}$

Fulfilling this vow involves expanding knowledge to include sociological understandings and implementing structural interventions to improve health. The current reliance on cultural competency to enhance communication with Black patients leaves pharmacists woefully incompetent, unprepared, and inattentive to the broader structural implications and its correlation with race. ${ }^{14}$ Evolving from cultural competence to structural competence acknowledges health is determined by socioeconomic conditions and physical environments. Structural competency also includes an understanding of the distribution of the social determinants of health.
Developing structural competence starts with studying structural health scholarship and other scholarship that describe systems of power (e.g., racism, patriarchy, classism, ableism, fat hostility, queer antagonism) as well as following the work of Black scholars in Africana, women's, gender, and sexuality studies. Additionally, pharmacy schools must re-assess current curricular standards and adopt these types of scholarship in pharmacy curricula to systematically prepare pharmacists to improve Black health. Without an understanding that the fundamental cause of health inequities is racist social, political, and economic structures and policies, pharmacists are not adequately improving their knowledge and competence to create practice and policy solutions to end health inequities.

\section{Recommendation 2: Value and listen to Black voices}

Oath 2: "I will hold myself and my colleagues to the highest principles of our profession's moral, ethical and legal conduct."

Ignoring, devaluing, erasing, and erasing, and excluding Black voices are morally and ethically wrong. Undeniably, it is impossible to improve Black health without the inclusion of Black voices in decision-making, problem awareness, assessments, and plans. Consequently, this vow requires pharmacy to investigate, examine, and assess the Black representation and belongingness at all levels, internal and external, to pharmacy institutions.

Questions to consider include: Is there proportional representation of Black voices in executive roles? Does Black representation match the representation of the communities served? Is there a culture of forced assimilation or a culture of authenticity? In other words, can Black people be themselves and still be admitted, graduated, accepted, hired, retained, promoted, recommended, and connected to power? Are Black voices embraced or rejected when it conflicts with the status quo? Is the Black presence tokenized or treated with dignity? Are Black people sacrificing their dignity to access safety in their livelihoods? Are they safe from violent microaggressions? Is there denial of racism or is racism rooted out?

Morally and ethically, it is imperative to include and hear from authentic, unapologetic Black voices in Black communities, places of education and instruction, employment, professional networks, and other pharmacy organizations to ensure and protect Black well-being.

\section{Recommendation 3: Locate the structural and social determinants of health to identify structural racism as the root cause of health inequities}

Oath 3: "I will consider the welfare of humanity and relief of suffering my primary concerns."

It is impossible to consider the welfare of humanity and its relief of suffering without an adequate understanding of racist societal structures, pastand present. Unfortunately, in the Accreditation 
Council for PharmacyEducation Doctor of Pharmacy standards, racism is not mentioned or named as a root cause of disease in the educational outcomes. ${ }^{15}$

Contrary to pharmacy curricula, race is not biological. "Race" is a socio-political construction that cultivates structural vulnerabilities to the health of communities of color. To consider the welfare of humanity and provide relief of suffering, it is imperative that when pharmacists are confronted with differences in health by race, they are properly trained to recognize and identify thehistorical insult, structural barriers, inaction in the face of need, societal norms, and unearned privileges. $^{8}$

To demonstrate how to critically analyze health inequities, review the water crisis in Flint, Michigan. Flint residents, which are $54 \%$ Black, have not had access to safe water to drink or cook for more than five years. ${ }^{16-17}$ This corrosive water, with lead leaching into its contents, caused a number of children to have elevated lead levels in their blood. Exposure to lead can result in a wide range of harmful and debilitating conditions such as damage to the brain and nervous system, learning and behavior problems, depression, irritability, hypertension, heart disease, and kidney disease. ${ }^{18}$ As racial health differences continue toemerge in Flint, pharmacists must identity the historical insult (e.g., contaminated water), structural barriers (e.g., abandonment of capital), inaction in the face of need (e.g., Black residents' complaints of the water ignored), societal norms (e.g., deteriorating Black health normalized), and unearned privileges (e.g., differential access to safe water) to identify the sociostructural determinants of health, implement structural interventions, and improve equitable access to the social determinants of health to optimize health.

Many may ignore the fundamental structural conditions that create contemporary health conditions, choosing instead to engage in racist biological determinism and victim-blaming. However, pharmacists have taken an oath to consider the welfare of humanity and relief of suffering as its primary concern. Consequently, pharmacists must identify sociostructural determinants of health, name structural racism, and recognize historical and contemporary injustices at the city, county, state, regional, and national level.

\section{Recommendation 4: Apply resources equitably, instead of equally, and collect robust data to assure optimal patient outcomes}

Oath 4: "I will apply my knowledge, experience, and skills to the best of my ability to assure optimal outcomes for my patients."

Apply resources equitably, not equally. Supposed "race neutral" policies will not resolve disease caused by racism. It is simply a fact that Black Americans are impacted disproportionately by COVID-19 and additional resources are required. Prioritizing testing is an example of a criteria that deserves special considerations. The Rainbow PUSH Coalition and National Medical Association jointly recommended that high-risk groups for testing include African-American, Latinx, and American Indian/Alaskan Native persons. ${ }^{19}$ On May 3, 2020, the CDC clinical criteria for testing considerations included "persons without symptoms who come from racial and ethnic minority groups disproportionately affected by adverse COVID-19 outcomes - currently African- Americans, Hispanics, and some American Indian tribes (e.g., Navajo Nation)." ${ }^{20}$ A few days later, however, the $C D C$ removed any mention of race in the CDC priorities for COVID-19 testing. The previously high priority status reserved for communities of color was supplanted by symptomatic hospitalized patients, healthcare facility workers, and residents in long-term carefacilities. ${ }^{21}$

The de-racialization of priority testing status held incalculable risks and concerns within Black communities due to the fact that Black persons have increased risk of exposure via disproportional representation in underpaid essential work, commuting to work via public transportation, and living in close quarters, all of which should have made this racial group a priority for testing to mitigate the spread of this disease to their families and other contacts, as well as reduce morbidity and mortality. ${ }^{22}$

Black Americans are overrepresented in nine out of the ten lowest-wage, high-contact essential jobs. They are disproportionately working as psychiatric aides, orderlies, nursing assistants, cooks/restaurant workers, pharmacy aides, food prep supervisors/servers, childcare workers, pharmacy technicians, and medical assistants. ${ }^{22}$ In New York City (NYC) Black people make up $24 \%$ of the population. ${ }^{1}$ However, they are overrepresented in frontline work specifically public transit (41\%); trucking, warehouse, and postal service (33\%); healthcare (32\%); and childcare, homeless, food, and family services (32\%). ${ }^{23}$ Of all the NYC frontline workers pre-pandemic, 55\% commuted via public transit and $48 \%$ had children living in the home. Consequently, these frontline workers, predominately people of color, are at an increased risk of exposure while at work, travelling to work, as well as potentially infecting their families upon returning home.

In addition to frontline workers, imprisoned and homeless communities are at an increased risk of exposure. Thirty-three percent of the nationwide prison population compared to $12 \%$ of the US adult population are Black due to a (un)recognized history of racist laws, over-policing, profiling, and more harsh sentencing of Black persons for criminal offenses. ${ }^{24}$ Being dispossessed within the prison system is dangerous for Black communities before and especially during a pandemic. National numbers show $40 \%$ of US America's homeless population is Black; segregation, housing discrimination, incarceration, access to quality health care, and other social determinants of health are most frequently the co-dependent culprits. ${ }^{25}$ Referring to recommendation 3 , it is imperative to identify the social and 
structural determinants of health to determine which groups are structurally vulnerable to less than optimal health.

Identification of all high-risk groups for exposure and severe illness is necessary to improve health outcomes and slow the spread of COVID-19. Contextualizing Black Americans as highpriority utilizes an equity-minded approach that applies resources based on need. An equality- minded approach, treating everyone equally, is inadequate to overcome the disproportional increased exposure and other COVID-19 related risks. Equity and equality are distinct from one another in that an equity-minded approach to reduce COVID-19 morbidity and mortality would result in the CDC prioritizing communities of color for testing which protects the most impacted, whereas seeking equality does not maximize the protection of marginalized communities.

The CDC includes healthcare workers as high-priority groups for testing but ideally, pharmacies are drafting policies to include all frontline workers, including non-healthcare workers. While some states like Ohio have identified people with underlying medical conditions, immunocompromised, and older patients as possessing a higher risk for COVID-19, it is limiting and disingenuous with the plethora of disproportionality data regarding COVID-19 to not include race and acknowledge the structural determinants of health in the testing criteria to include high-contact essential workers as well as those residing in densely-packed metropolitan areas, possessing a positive incarceration history, and/or experiencing housing insecurity.

Pharmacy must make the invisible high-priority groups visible by prioritizing testing and other resources accordingly as well as recommending this visibility in the public, private, and nonprofit sectors. Furthermore, to assure optimal patient outcomes, pharmacy should position themselves to be part of partnerships to responsibly, respectfully, and anonymously collect robust data from those testing positive for COVID-19 such as mode of transportation, type of housing, work conditions, income level, food access, incarceration history, and many other social determinants of health; pharmacists are trained to collect social histories and other subjective information. Then dashboards or data visualization tools could be created to comprehensively identify trends and enable targeted solutions based on social determinants of health. The pooling and systematic tracking of this data at the community, county, regional, state, and federal level would undoubtedly allow for more effective problem solving.

Pharmacists can apply resources equitably, instead of equally, to assure optimal patient outcomes. They are trusted individuals with indispensable skills to improve the health of Black lives disproportionately impacted by COVID-19, and now is the time for pharmacy to operate with more intentional assurance.

\section{Recommendation 5: Respect and protect the personal and health information of all Black lives}

Oath 5: "I will respect and protect all personal and health information entrusted to me."

At the start of the pandemic, several states and organizations released Crisis Standards of Care guidelines prioritizing care to patients with a longer life expectancy based on personal and health information. ${ }^{26}$ These guidelines can be inherently racist, harmful, and unfair to Black Americans who already face sociostructural inequities jeopardizing their health. They are encountering a double whammy as these guidelines may punish Black bodies by deprioritizing care for health vulnerabilities imposed by structural inequities. To genuinely respect and protect all personal health information obliges a comprehensive understanding of an individual and theirenvironmental contexts.

Current guidelines developed to conserve resources based on health information will likely harm Black communities, already marginalized by healthcare and other institutions. Guidelines must be informed by various contemporary and historical inequities. Race and other identities, therefore, must be factored into decision making to protect Black lives, especially the ones at the extreme margins of society.

It is not enough to say "Black Lives Matter" when the inequities shaping ALL Black lives are largely ignored in policies and practice. Black persons hold and operate from multiple marginalized identities. To assess Black patients holistically, it is paramount to utilize an intersectional prism to view the many junctions at which they exist such as socioeconomic class, ability status, gender, size, religion, immigration status, and sexuality. ${ }^{27}$ Pharmacists, consequently, must pay attention to racism at the intersection of classism, ableism, patriarchy, sizeism, Christian normativity, immigration hostility, and queer antagonism when crafting guidelines and policies.

Patients do not want to be shamed or blamed for their identities or health during clinical interactions, rather, they deserve to be understood and embraced. Cultivating an understanding of structural inequities (e.g., redlining, Jim Crow, $13^{\text {th }}$ amendment) to identify the unequal distribution of the social determinants of health (e.g., neighborhood demographics, safety, incarceration) will mitigate pharmacist bias and provide them with the capacity to accurately respect and protect all personal and health information. ${ }^{28-31}$

\section{Recommendation 6: Advocate for Black lives in personal and professional networks}

Oath 6: "I will embrace and advocate changes that improve patient care."

Advocacy is an important tool to optimize health outcomes. This section describes examples of advocacy efforts pharmacists can 
take inside and outside their place of employment to improve socioeconomic status, physical environments, and access to clinical care for Black communities.

Income, air quality, housing, transit, and access to clinical care are examples of factors necessitating attention by pharmacists to improve the quality and length of life for Black persons. Strong advocacy for living wages for all employees based on the local cost of living as well as increased hazard pay due to COVID-19 exposure are some important strategies to achieve income equality. To minimize COVID-19 exposure for essential workers to improve the work environment, pharmacists should advocate for Personal Protective Equipment (PPE). They should also push for forward-thinking partnerships with corporate entities such as hotels that might be relied upon to isolate employees if they become COVID-19 positive, simply prefer to stay closer to work in order to reduce their public transit use, and/or choose to avoid the risk of unknowingly infecting their families. ${ }^{23}$ Moreover, pharmacists should champion for the expansion of healthcare to include access for newly-hired workers and hourly workers, reduction of high deductibles, and increasing the number of clinicians in-network. ${ }^{32}$

Pharmacists can play an integral role in advocating for policies within their workplace and other institutions to end Black-white health inequities.

\section{Recommendation 7: Prepare the next generation of pharmacists to engage in structurally competent care}

Oath 7: "I will utilize my knowledge, skills, experiences, and values to prepare the next generation of pharmacists."

Systematically and sustainably preparing the next generation of pharmacists to critically evaluate structural inequities and implement structural interventions could end inequities. Curricular changes that involve teaching students the impact of slavery, Jim Crow, 13th amendment, redlining, GI bill, and other structural inequities on the distribution of the social determinants of health are crucial and key in preparing students to identify and dismantle the root causes of disease. Prospective pharmacists should be taught by scholars examining racism, patriarchy, classism, ableism, queer hostility, fat antagonism, and other systems of power in the context of Africana studies. These required lessons should start in their first year of pharmacy school as standalone courses and threaded in every course until graduation.

Passing on these referenced recommendations to student pharmacists to support Black lives during COVID-19 is critical to improving health currently and post-COVID-19. Sadly, much of what is discussed in this manuscript and summarized below is missing from pharmacy curricula. ${ }^{33}$

\section{Summary/Conclusion}

Numerous health factors impact the quality of life and life expectancy for Black communities. Commonly, socioeconomic factors and physical environments are ignored while personal choices and clinical care are highlighted to describe the Blackwhite health gap. Nevertheless, achieving racial health equity requires pharmacists to comprehend, identify, and assess how the structural determinants of health impact the maldistribution of the social determinants of health.

Although race is biological fiction (i.e., races are not genetically discreet), our global engagement with coronavirus illustrates racial inequities by way of racist policies, practices, and norms within institutions and systems. COVID-19 is making subtle, structural inequities explicitly visible. Structural racism cultivates environments where Black people have increased exposure and diminished capacity to fight COVID-19 because of underlying diseases from navigating a lifetime of racism at the convergence of other systems of power. The virus may not discriminate, but the exposure (e.g., residing in concentrated poverty, utilization of public transit, overrepresentation in essential work) and effects of the disease based on discriminatory and racialized structures most assuredly does. Consequently, Black Americans are at a decided disadvantage to their white counterparts, who maintain distinct health advantages before and in the face of Covid-19. ${ }^{34}$

With Covid-19, (untrue) marketing messaging and news headlines such as "we are all in this together" quickly surfaced. Some institutions worked to find affordable housing for homeless communities and low-income workers, released prisoners to increase social distancing behind walls in correctional facilities, made jobs more accessible through video conferencing, increased pay for essential workers, expanded accessibility of healthcare by way of telemedicine, and created many other initiatives to reduce the spread of COVID-19. ${ }^{35}$ These strategies are helpful, however, multiple, sustained interventions are required at the local, regional, and national level. Systematically crafting and expanding strategies towards radical sociostructural transformation and away from personal choices to undo oppressive socio-political structures and policies can mitigate the effects of structural racism and other inequities, thereby optimizing health. ${ }^{36}$

These strategies should center the needs of individuals at the margins and extreme margins. Questions such as who is believed when they present with symptoms, possesses the ability to advocate for their own health, and/or has the privilege to remain at home during this global pandemic are necessary in problem awareness and centering at the margins. It is easier, for example, to assuage COVID-19 risks with financial cushions, occupations with low contact, owning a personal vehicle, living in sparsely populated areas, and/or not being incarcerated. It is important to assess which groups experience structured vulnerability to their health from various oppressive systems as well as which groups 
widen health inequities by hoarding resources and power to alleviate their COVID-19 risks. ${ }^{34}$

Variances in health will persist if systems that subtly and structurally prefer one race over the other continue to thrive. While internalized and interpersonal racism are significant, dismantling structural racism is primary to resolving the former two levels. ${ }^{8}$ Without structural racism, there would not be differences across groups to internalize and treat differently in interpersonal interactions.

Supporting Black lives requires nuance, unpacking internalized inequities, confronting America's racist roots, dismantling subtle and overt forms of white supremacy, as well as naming and understanding the levels of racism. Pharmacists are a highly trusted profession and have made promises to devote themselves "to a lifetime of service to others through the profession of pharmacy" which requires them to achieve structural competency, value Black voices, understand race as a socio-political construction, name racism, identify historical and contemporary injustices, locate structural determinants of health, apply resources equitably based on need, collect robust data to solve complex problems, diminish bias, see patients holistically in the contexts of inequalities and inequities, and advocate for Black lives.

Structural racism not only impacts Black people but all communities of color, and it is imperative that future discussions on the role of pharmacists include analyzing the impacts of COVID- 19 on Indigenous, Latinx, and Asian communities. Pharmacists are uniquely positioned through their knowledge, skills, and resources to attenuate the effects of structural racism andsupport Black lives, and it is incumbent upon everyone in the field to embrace necessary changes that will benefit the communities pharmacists are tasked with serving.

\section{References}

1. US Census Bureau Quick Facts: United States. Available online:

https://www.census.gov/quickfacts/fact/table/US/PS\%20T 045219 (accessed on 13 May 2020).

2. Cases in the US. Available online: https://www.cdc.gov/coronavirus/2019-ncov/casesupdates/cases-in-us.html (accessed on 13 May 2020).

3. COVIDView A Weekly Surveillance Summary of US COVID19 Activity. Available online: https://www.cdc.gov/coronavirus/2019-ncov/coviddata/covidview/index.html (accessed on 13 May 2020).

4. Provisional Death Counts for Coronavirus Disease (COVID19): Weekly Updates by Select Demographic and Geographic characteristics. Available online: https://www.cdc.gov/nchs/nvss/vsrr/covid weekly/i ndex.htm\#Race Hispanic (accessed on 13 May 2020).

5. Opinion | Why Coronavirus Is Killing African- Americans More Than Others. Available online: https://www.nytimes.com/2020/04/14/opinion/sund ay/coronavirus-racism-african- americans.html?auth=loginfacebook (accessed on 13May 2020).
6. Health Factors | County Health Rankings and Roadmaps. https://www.countyhealthrankings.org/explore- healthrankings/measures-data-sources/county- health-rankingsmodel/health-factors (accessed on13 May 2020).

7. Auburn A, Brown A, Grady J. External Factors vs. Right Choices: Findings From Cognitive Elicitations and Media Analysis on Health Disparities and Inequities. Louisville, KY: Cultural Logic; 2007.

8. Jones C. Levels of racism: a theoretic framework anda gardener's tale. American Journal of Public Health. 2000;90(8):1212-5.

9. Williams DR, Williams DR, Mohammed SA, Mohammed SA. Discrimination and racial disparitiesin health: evidence and needed research. Journal ofBehavioral Medicine. 2009;32(1):20-47.

10. Black People Are Dying From COVID-19 at Higher Rates Because Racism Is a Preexisting Condition. Available online: https://www.motherjones.com/coronavirusupdates/2020/04/black-people-are-dying-from-covid- 19-athigher-rates-because-racism-is-a-pre-existing- condition/ (accessed on 13 May 2020).

11. Banaji MR, Greenwald AG. Blindspot: hidden biases ofgood people. 1st ed. New York: Delacorte Press; 2013.

12. Hardeman RR, Medina EM, Kozhimannil KB. Structural Racism and Supporting Black Lives - TheRole of Health Professionals. The New England Journal of Medicine. 2016;375(22):2113-5.

13. Oath of a Pharmacist / American Pharmacists Association. Available Online: https://www.pharmacist.com/oathpharmacist(accessed on 13 May 2020).

14. Metzl JM, Roberts DE. Structural competency meets structural racism: race, politics, and the structure ofmedical knowledge. The virtual mentor: VM. 2014;16(9):674-90.

15. Accreditation standards and key elements for the professional program in pharmacy leading to the doctor of pharmacy degree ("Standards 2016"). Accreditation Council for Pharmacy Education; 2 February 2015 Accessed 4 Aug 2020

https://www.acpeaccredit.org/pdf/Standards2016FIN AL.pdf

16. Flint city, Michigan; United States. Available online: https://www.census.gov/quickfacts/fact/table/flintcit ymichigan,US/PST045219 (accessed on 13 May 2020)

17. Flint Water Crisis: Is the Water Clean Now? Availableonline: https://www.npr.org/2019/04/25/717104335/5- yearsafter-flints-crisis-began-is-the-water-safe https://www.cnn.com/2016/03/04/us/flint-water- crisisfast-facts/index.html (accessed on 13 May 2020).

18. Lead: Health Problems Caused by Lead - NIOSH Workplace Safety and Health Topic. Available online: https://www.cdc.gov/niosh/topics/lead/health.html (accessed on 13 May 2020).

19. Joint Statement on the Response to the Coronavirus/COVID-19 Pandemic. Available online: https://www.nmanet.org/news/503170/Joint- Statementon-the-Response-to-the- CoronavirusCOVID-19Pandemic.htm (accessed on 13May 2020).

20. CDC Reverses Course Again On Using Race As Testing Criteria. Available online: https://www.wvxu.org/post/cdcreverses-course- again-using-race-testing-criteria\#stream $/ 0$ (accessedon 13 May 2020) 
21. Interim Guidance: Healthcare Professionals 2019- nCoV. Available online: https://www.cdc.gov/coronavirus/2019ncov/hcp/clinical-criteria.html (accessed on 13 May2020).

22. COVID-19: Investing in black lives and livelihoods. Available online:

https://www.mckinsey.com/ /media/mckinsey/industries/ public\%20and\%20social\%20sector/our\%20insights/covid\%2 019\%20investing\%20in\%20black\%20lives\%20and\%20livelih oods/covid-19-investing-in-black-lives-and-livelihoodsreport.pdf (accessed on 13 May 2020)

23. New York City's Frontline Workers. Available online: https://comptroller.nyc.gov/reports/new-york-citysfrontline-workers/ (accessed on 13 May 2020).

24. Gap between number of blacks, whites in prison narrows. Available online: https://www. pewresearch.org/facttank/2019/04/30/shrinking-gap-between-number-ofblacks-and-whites-in-prison/ (accessed 13 May 2020).

25. Racial Disparities in Homelessness in the United States National Alliance to End Homelessness. Available online: https://endhomelessness.org/resource/racial-inequalitieshomelessness-numbers/ (accessed on13 May 2020).

26. Opinion: Race Disparities Built In To COVID-19 Treatment Guidance For Hospitals: Shots - Health News. Available online: https://www.npr.org/sections/healthshots/2020/04/21/838763690/opinion-u-s-must- avoidbuilding-racial-bias-into-covid-19-emergency- guidance (accessed on 13 May 2020).

27. Framing Questions on Intersectionality. Available online: https://ushrnetwork.org/uploads/Resources/framing questi ons on intersectionality 1.pdf (accessed 13 May 2020).

28. Avant ND, Gillespie GL. Pushing for health equity through structural competency and implicit bias education: A qualitative evaluation of a racial/ethnichealth disparities elective course for pharmacy learners. Currents in Pharmacy Teaching and Learning. 2019;11(4):382-93.

29. Avant ND, Weed E, Connelly C, Hincapie AL, Penm J. Qualitative Analysis of Student Pharmacists' Reflections of Harvard's Race Implicit Association Test. Currents in Pharmacy Teaching and Learning. 2018;10(5):611-7.

30. Avant ND, Davis RD. Navigating and SupportingMarginalized Identities in Dominant Pharmacy Spaces. Innov Pharm. 2019; 9(4).

31. Avant, ND, Penm J, Hincapie AL, Gillespie GL. "Not to Exclude You, But...": Characterization of Pharmacy Student Microaggressions and Recommendations forAcademic Pharmacy. Curr Pharm Teach Learn. 2020; 12(10):11711179.

32. Clinical Care. Available online: https://www.countyhealthrankings.org/explore- healthrankings/measures-data-sources/county- health-rankingsmodel/health-factors/clinical-care (accessed on 13 May 2020).

33. Arya V, Butler L, Leal S, et al. Systemic racism: Pharmacists' role and responsibility. Journal of the American Pharmacists Association. 2020;60:e43-e46.

34. Jones CP, Jones CY, Perry GS, Barclay G, Jones CA. Addressing the Social Determinants of Children's Health: $A$ Cliff Analogy. Journal of Health Care for thePoor and Underserved. 2009;20(4):1-12.
35. COVID-19: A Human Rights Checklist. Available online: https://www.hrw.org/news/2020/04/14/covid-19- humanrights-checklist (access 13 May 2020).

36. Crear-Perry J, Correa-de-Araujo R, Lewis Johnson T, McLemore MR, Neilson E, Wallace M. Social and Structural Determinants of Health Inequities in Maternal Health. Journal of women's health (Larchmont, N.Y. 2002). 2021;30:23-235. 